\title{
Routine Activity Theory and Farm Equipment Theft: A Macro-Level Approach
}

\author{
Dustin L. Osborne, Ph.D. \\ Department of Criminal Justice and Criminology \\ East Tennessee State University \\ Box 70555 \\ Johnson City, TN 37614 \\ Kristin Swartz, Ph.D. \\ Department of Criminal Justice \\ University of Louisville \\ 2301 S. $3^{\text {rd }}$ Street, Brigman Hall \\ Louisville, KY 40292
}

Corresponding author: Dustin L. Osborne; osbornedl@etsu.edu, (423) 439-5604

\begin{abstract}
Though a handful of studies have explored the relationship between farm characteristics and theft of farm equipment, all have been focused at the micro level. Put differently, they have sought to determine whether a relationship exists between likelihood of theft victimization and the characteristics (e.g., size, location) of individual farming operations. The current study builds upon this work by seeking to determine whether county-level factors (in line with the routine activity theory framework) serve to influence the incidence of farm equipment theft within counties. Data are derived from the National Incident-Based Reporting System, the Census of Agriculture and the United States Census of the Population. Results are on the whole supportive of the theory's application to the problem and suggest that macro-level investigations constitute a worthwhile approach to better understanding agricultural victimization.
\end{abstract}

Keywords: Farm equipment theft; routine activity theory; rural crime 


\section{Introduction}

Recent decades have featured increased attention to offending in rural communities, as researchers have sought to explore forms (e.g., moonshine production, poaching, timber theft) that are unique to the rural environment (see Green, 2011; Green, 2016; Mortimer et al., 2005; Serenari \& Peterson, 2016 for examples). One such example, the theft of farm equipment, has been the focus of several empirical studies to date, as we have sought to develop an understanding of its prevalence and the factors that serve to influence risk of victimization (Barclay \& Donnermeyer, 2011; McIntyre et al., 2017). These studies have focused on the micro level, seeking to assess the relationship between the characteristics of individual farming operations and theft history (see Bunei et al., 2012; McIntyre et al., 2017; Mears et al., 2007 for examples). Though beneficial, this strategy does not allow for the development of a macro-level understanding of the problem. The current study seeks to address this gap in the literature by determining whether routine activity theory (applied at the macro level) has applicability to the crime of farm equipment theft. It does so by aggregating characteristics of farming operations at the county level and assessing their overall influence on county-level counts of theft.

Attempts to understand the prevalence of farm equipment theft suggest that it is relatively common in rural communities (Barclay \& Donnermeyer, 2011). One of the earliest studies of this type made use of survey data gathered from 531 famers in Tennessee during the late 1980's. Cleland (1990) found that $17 \%$ had been victimized in the 12 months prior to administration, with the majority of thefts involving some type of farm equipment. Similar results emerged from an exploratory study in Alabama in the early 1990's, as 34\% of surveyed farmers $(\mathrm{N}=428)$ reported being past victims of theft (Dunkelberger et al., 1992). The targets of these thefts ranged from hand tools to more expensive pieces of equipment (e.g., tractors). The research literature indicates that the problem has not declined in the last three decades. For example, Mears et al. (2007) found that $29 \%$ of surveyed farm operators in California $(\mathrm{N}=823)$ had been victimized by small equipment theft in the previous 12 months. In addition, approximately 14\% reported having larger pieces of equipment stolen. McIntyre et al. (2017) suggest similar rates of victimization for farmers in Georgia, as 33\% of the 415 survey participants claimed to have been the victims of theft in the prior year.

It is important to note that a limited number of empirical investigations hinder our ability to make generalizations regarding the prevalence of equipment theft, as all make use of relatively small samples and/or are restricted to limited geographic areas. However, their findings suggest that theft may in fact be prevalent and thus promote the need for additional exploration of the relationship between farm-related characteristics and victimization risk. What follows is a review of the literature on the routine activity perspective and past applications of the theory to farm equipment theft at the micro level. 


\section{Routine Activity Theory}

Routine activity theory is essentially a theory of opportunity, suggesting that the presence of opportunities within the built environment is critical to understanding the prevalence of offending (Cohen \& Felson, 1979; Felson \& Clarke, 1998). Its core tenets can be broadly classified into two separate hypotheses. First, individuals who are motivated to offend are likely to act upon this motivation when a certain set of conditions converge to culminate in the commission of a criminal act. Specifically, a motivated offender must converge in time and space with an attractive target lacking in guardianship in order for a crime to occur (Cohen \& Felson, 1979). Second, and also at the macro level, broad patterns of movement and production serve to condition the prevalence of offending seen within communities and larger areas (Cohen \& Felson, 1979; Messner \& Blau, 1987). Routine activity theory at the macro-level is not wholly unique from its micro-level counterpart. That is, it suggests that the overall prevalence of criminal opportunities is dictated by the aggregate convergence in time and space of motivated offenders, attractive targets, and a lack of guardianship (Cohen \& Felson, 1979). Thus, conditions that exist within communities, counties, and larger areas serve to structure the number of attractive targets located within the awareness space of offenders, as well as the ability for interested parties to take guardianship over property, places, or those motivated to offend.

Offering support for their conceptualization of routine activity theory at the macro level, Cohen and Felson (1979) found that the introduction of females into the workplace in the 1970s served to create an environment in which home burglaries were more common. At the micro level, families in which the husband and wife both worked were more likely to become victims of burglary than their counterparts featuring a spouse who remained at home during the day. At the macro level, areas with a higher rate of dual-spouse employment were more likely to experience higher rates of burglary than areas featuring lower rates of such employment, providing support for the assertion that community-level incidence of crime may reflect the aggregate risk presented by phenomena occurring at the micro level.

Messner and Blau (1987) lend additional credence to this argument. The researchers examined data for 124 metropolitan statistical areas in the early 1980s in an attempt to discern whether routine leisure activities at the aggregate level have influence upon rates of various types of offending. Leisure activities under analysis were amount of time spent watching television, and the density of sports and entertainment venues. Messner and Blau (1987) posited that statistical areas featuring a higher proportion of the population spending substantial time watching television would experience lower levels of crime due to individuals residing within the safety of their home. On the other hand, they hypothesized that a higher density of sports and entertainment venues would suggest that more individuals venture out on a regular basis, thus increasing the number of suitable targets in the awareness space of offenders. Controlling for other potential correlates of crime, the researchers found that television viewing shared a negative correlation with a variety of crime types (i.e., forcible rape, robbery, burglary). Furthermore, results revealed that a positive relationship 
existed between these crimes and the density of entertainment venues within each MSA. Thus, their results were supportive of their initial hypotheses, and suggest that aggregate lifestyle choices have influence on the prevalence of a variety of offense types.

Copes (1999) took a similar macro-level approach in attempting to understand the applicability of routine activity theory to automobile theft at the census-tract level. Available data were assessed for 41 such tracts in the Southeastern United States. Suitable target was operationalized as road density and car density, with Copes (1999) positing that higher levels indicated the presence of more opportunities for motivated offenders. Results were generally supportive of this assumption. A combined measure (created by summing z-scores for both road density and car density) shared a statistically-significant, positive relationship with motor vehicle theft. Thus, tracts with higher densities of roads and cars were more likely to suffer from higher levels of theft.

Based upon the results of these studies, it appears as if macro-level applications of routine activity theory provide a useful framework with which to understand offending rates; specifically, the incidence of property crime. Thus, application of the theory to farm equipment theft seems to offer the potential to increase our understanding of the problem. With that in mind, attention is turned to discussing past attempts to explore the relationship between routine activities and farm-related theft at the micro level, and how similar research questions can be answered in relation to macro-level data.

\section{Routine activity theory and farm equipment theft}

To date, a limited number of studies have sought to apply elements of routine activity theory (at the micro level) to explore agricultural theft. For example, Mears et al. (2007) utilized data from 823 farmers in eight California counties to discern whether measures associated with target attractiveness, exposure, proximity and guardianship played a role in the likelihood of victimization. Results of the study provided partial support for the role that opportunity plays in farm equipment theft. Theft of smaller equipment (targets more portable in nature and thus potentially more attractive) was more likely than theft of larger equipment (e.g., tractors). Farms employing a higher number of workers were more likely to suffer from victimization, suggesting that employee theft may be an issue for some operations. This possibility has been highlighted in other discussions of agricultural crime (see Swanson et al., 2002 for an example), and is a reality that many forms of industry regularly face. In addition, farms lacking in guardianship were more likely to be victimized by theft than those which employed a high number of security and surveillance measures. Finally, bivariate analysis suggested that larger farms may be more likely to be victimized than those featuring less total acreage (rationalized by the assumption that large farms potentially present less opportunity for effective surveillance).

Bunei et al. (2013) conducted a similar investigation utilizing survey data from 200 Kenyan farmers. They found that farms located closer to densely populated areas were more likely to be victimized than those located in remote locations (suggesting that dense 
populations may present the opportunity for potential offenders to become aware of theft opportunities). Furthermore, they found that large farms suffered from higher theft incidence than did small farms, and that farms employing a higher number of workers were more likely to experience theft than those without hired labor, or a comparatively low number of workers. These findings are consistent with those revealed by Mears et al. (2007), and generally supportive of the importance of guardianship and offender awareness in conditioning the victimization risk of individual farming operations.

Other studies (though not designed to be direct tests of the routine activity framework) offer additional support. Their findings indicate that victimization is more likely for larger farms (Dunkelberger et al., 1992; Farmer \& Voth 1989; McIntyre et al., 2017), farms located near densely-populated (e.g., urban) communities (Farmer \& Voth, 1989) and roadways (George Street Research, 1999), and those employing workers (McCall, 2003). Taken as a whole, these findings merit the continued application of the routine activity framework in attempts to further our understanding of the problem.

\section{The Current Study}

The current study seeks to determine whether routine activity theory has applicability to farm equipment theft at the macro level. Though no study to date has attempted to assess this potential relationship, Barclay and Donnermeyer (2011) suggest that a macro-level approach may allow for a better understanding of the problem. It is important to note that several of the findings revealed by micro-level studies are difficult to test at the macro level. For example, no publically available dataset provides an overview of the miles of road contained within each county in the United States. Similarly, without surveying all farmers within each county, no inference can be made regarding the security measures employed within them. With that said, there are still a number of research questions that can be answered through available data that are in line with the literature, and rooted in a routine activity framework.

Research question \#1: Does the average size of farms contained within a county influence the number of farm equipment thefts experienced by it?

As discussed, the literature suggests that larger farms are at a greater risk of being victimized than those smaller in acreage (Dunkelberger et al., 1992; Farmer \& Voth, 1998; McIntyre et al., 2017; Mears et al., 2007). As such, it seems plausible that counties featuring farms of higher average acreage would feature higher theft counts.

\section{Research question \#2: Do counties that are more densely-populated experience higher counts of farm equipment theft than counties less densely-populated?}

The literature on farm equipment theft at the micro level indicates that farms in proximity to densely populated areas are at greater risk of victimization than those located away from these areas (Bunei et al., 2013; George Street Research, 1999). At the county evel, 
this would suggest that farms located within counties featuring higher population density will suffer from higher incidence of theft. Routine activity theory would posit that more densely populated counties present the potential for more motivated offenders to become aware of attractive targets on farming operations, culminating in the higher incidence of theft.

Research question \#3: Do counties featuring a higher on-average number of hired workers per farm experience a higher count of farm equipment theft than counties featuring a lower on-average number of hired workers per farm?

Past research has suggested that farms employing workers are at greater risk of being the victims of farm equipment theft (Dunkelberger et al., 1992; McCall, 2003; Mears et al., 2007). Because those working on farming operations become fully aware of the equipment in use by them, the manner and location in which they are stored, and the patterns of the farm owner, they are in a unique position to act upon an attractive target if they are motivated to offend. Even if they are not, they may reveal details of the farm's operations to someone who is, in effect providing the information necessary regarding the offense opportunity to others. It would follow that counties featuring a higher on-average number of workers per farm may suffer from higher incidence of farm equipment theft.

Research question \#4: Do counties featuring a higher aggregate value of farm equipment suffer from increased incidence of theft?

Routine activity theory would suggest that criminal offending is more prevalent when attractive targets are more plentiful in nature, or when available targets are of high monetary value (Cohen \& Felson, 1979). In line with this suggestion, it would seem likely that those counties featuring a higher aggregate value of equipment would experience higher incidence of theft.

Research question \#5: Do counties featuring a higher proportion of land dedicated to farming operations experience higher theft incidence?

Counties featuring a higher proportion of land dedicated to farming operations would seemingly present more opportunities for theft of farm equipment due to the availability of attractive targets and the proximity of potential offenders to farming operations.

Research question \#6: Do counties featuring a higher proportion of farm operators whose primary occupation is farming feature lower incidence of theft?

As previously discussed, past research has suggested that victimization is partially influenced by the level of surveillance and guardianship present on agricultural operations (Bunei et al., 2013; Mears et al., 2007). It would seem reasonable to hypothesize that fulltime farmers would be better able to provide effective guardianship than their counterparts who hold another primary occupation. As such, the current study hypothesizes that counties 
featuring higher proportion of full-time farmers will also feature higher levels of guardianship, and thus lower counts of farm equipment theft.

\section{Methodology}

\section{Data}

Data for the current study are drawn from three separate sources: The United States Census, the National Incident-Based Reporting System (NIBRS), and the 2007 Census of Agriculture. Information regarding population density is made available through the 2010 iteration of the United States Census, with the current study relying upon reported population figures for each county included in the current analysis. NIBRS — overseen by the Federal Bureau of Investigation - provides event-specific information for crime incidents reported by participating law enforcement agencies (approximately $29 \%$ of the U.S. population is covered by such agencies) (McCormack et al., 2017). It allows for a determination of the type of property taken in each reported theft incident, with farm equipment being one possible classification (U.S. Department of Justice, 2017). The current study uses information contained within the 2011 and 2012 iterations of the NIBRS dataset to create the dependent measure under analysis - count of farm equipment thefts reported within each county.

The Census of Agriculture - administered by the United States Department of Agriculture (USDA) every five years - provides an overview of farming operations within the United States (via surveys of farm operators). Survey findings are broken down by both states and the counties contained within them. Because the goal of the Census of Agriculture is to arrive at a comprehensive understanding of farming operations, all agricultural operations (defined as any operation that will produce or sell at least $\$ 1,000$ worth of agricultural products in a given year) known to the USDA are included within the sampling frame (National Agriculture Statistics Service, 2014). Each Census of Agriculture contains information on a number of variables, ranging from operator characteristics to operation characteristics. These variables allow for measures relating to routine activity theory to be created at the county level for use in the current study.

\section{Sample}

Selection of counties to include in the sample under analysis requires consideration of the following: (1) NIBRS certification status of law enforcement agencies within each county, (2) certification status at the state level, and (3) geographic concerns. Only a fraction of enforcement agencies are NIBRS-certified (Justice Research and Statistics Association 2013). The current study attempts to assess correlates of equipment theft at the county level, rendering it necessary to select counties for which all enforcement agencies feature NIBRS certification (e.g., sheriff's departments, municipal departments). It is also essential to select counties housed within states that feature $100 \%$ NIBRS participation, as state-level departments (e.g., state police) may respond to calls regarding farm equipment theft. Finally, 
it is important to account for the differences in farm structure and agricultural production techniques that exist between geographic areas. For example, results from the Census of Agriculture suggest that counties located in Southern States on the whole feature different farming characteristics (e.g., size, crops produced, equipment utilized) than those in the Midwest. As such, it is deemed useful to restrict counties included within the final sample to those located within a uniform geographic area.

Taking these considerations into account, the analysis for the current study is restricted to counties located within the Southern Region of the United States. These counties are drawn from the four states within the Region that feature 100\% NIBRS certification: Virginia, South Carolina, Tennessee and Arkansas. A total of 311 counties are housed within these states, constituting the final sample.

\section{Dependent measure}

The current study treats the count of farm equipment thefts reported for each county as the dependent measure. Two indicators within the NIBRS dataset allow for construction of the measure. First, each incident included within the dataset is identified by the state in which it occurred. Second, an identifier for the law enforcement agency that filed the report is listed. Data are first pulled for the four states included within the sample. Next, an internet search allows for a determination of the counties in which each reporting agency is located. A final count of farm equipment thefts for each county is thus inclusive of all incidents reported by sheriff's departments, municipal police, and state-level agencies operating within them.

Making use of theft counts for a single year allows for potential bias in the findings, as they may represent an aberration. For example, a county can experience theft counts for one year that are not representative of the typical prevalence of farm equipment theft. The current study accounts for this by utilizing the aggregate count of thefts over a two-year window (2011 and 2012) and then dividing that figure by two. This technique is frequently utilized in social science research, as it provides for increased stability and confidence in the measure (see Roman et al., 2008; Smith et al., 2000; Wilcox et al., 2004 for examples).

\section{Independent measures}

The measure for population density is derived from the 2010 version of the U.S. Census, and is calculated as the number of individuals residing in the county divided by the total square miles of property contained within it. Thus, population density is measured as the number of individuals per square mile. Because data for this measure is highly skewed, the natural log is utilized in the regression model employed in the analysis.

All other routine activity measures are calculated from data provided by the 2007 version of the Census of Agriculture. Average farm size is operationalized as the total acreage of farmland present within a county divided by the total number of farms contained within it. Worker density is calculated as the total number of workers reported by farms within each 
county divided by the total number of farms present - and can be interpreted as the average number of workers per farm within the respective county. The equipment value attributable to each county is the aggregate value (in dollars) of equipment reported by each individual farming operation contained within it. Because values are large (the lowest value of equipment contained in any one county is approximately $\$ 2$ million), the raw value is divided by $\$ 100,000$ in order to provide a measure that is more easily interpretable in the multivariate analysis. Proportion farmland is calculated as the total number of acres dedicated to farming operations divided by the total land area (also in acres) contained within the respective county's borders. Finally, full-time farmers represents the proportion of farm operators within each county whose primary occupation is farming and is calculated by dividing the number of full-time operators by the number of farms present.

\section{Plan of analysis}

Analysis for the current study proceeds in three stages. The first entails presentation of the descriptive statistics for all included measures. Stage two involves a discussion of the bivariate correlations, which provide an initial understanding of the relationships that exist between the measures. The third and final stage makes use of negative binomial regression to determine the unique impact that each of the independent measures has upon count of farm equipment thefts when controlling for other predictors. Negative binomial regression is most appropriate for the analysis due to the fact that the dependent measure takes the form of count data (Hardin \& Hilbe, 2012; Hilbe, 2011), and is not normally distributed (over-dispersion of the measure) (Hilbe, 2011).

\section{Results}

A summary of the descriptive statistics for the dependent and independent measures can be found in Table 1 . The average county features approximately 15 incidents of farm equipment theft $(\mathrm{M}=15.21)$. A good amount of variation exists within the measure, rendering the variance (264.40) higher than the mean. As previously discussed, this finding requires the analysis to rely upon negative binomial regression for making inferences on the relationship between individual predictors and the dependent measure. In relation to the routine activity measures, the average county features a population density of 133.11 individuals per square mile of land, approximately $\$ 45$ million in equipment value in use by the farms contained within it, ,and an average of less than one hired worker (worker density) per farm $(\mathrm{M}=0.21)$. Further, the counties in the sample have an average farm size of approximately 236 acres, $37 \%$ of contained land dedicated to farming operations, and approximately $42 \%$ of farm operators claiming farming as their primary occupation. 
Table 1: Descriptive Statistics

\begin{tabular}{lcccc}
\multicolumn{1}{c}{ Measure } & Mean & SD & Minimum & Maximum \\
& & & & \\
Farm Equipment Theft & 15.21 & 16.26 & 1.00 & 109.00 \\
Population Density & 133.12 & 258.61 & 8.54 & 2766.77 \\
Worker Density & 0.21 & 0.09 & 0.03 & 0.77 \\
Equipment Value* & 452.29 & 316.36 & 19.91 & 1673.06 \\
Average Farm Size & 235.91 & 231.24 & 28.89 & 1550.91 \\
Proportion Farmland & 0.37 & 0.19 & 0.02 & 0.98 \\
Full-Time Farmers & 0.42 & 0.08 & 0.21 & 0.70
\end{tabular}

*Note: The raw equipment value is divided by $\$ 100,000$ in order to provide a measure that is more easily depicted in the table.

\section{Bivariate correlations}

Table 2 contains a full summary of the bivariate correlations representing the relationships between the measures included within the analysis. The nature of the dependent measure (overdispersed count data) renders biased coefficients between it and the independent measures (Chen \& Popovich, 2002). As such, interpretation of these coefficients should be treated with caution.

Table 2: Bivariate Correlations

$\begin{array}{llllllll}\text { Measure } & 1 & 2 & 3 & 4 & 5 & 6 & 7\end{array}$

1. Theft

2. Population Density $\quad .27 * * \quad--$

3. Worker Density $\quad .11 \quad-.06$

4. Equipment Value $\quad .39 * * \quad-.05 \quad .22 * * \quad--$

5. Average Farm Size $\quad .08 \quad-.19^{*} \quad .55^{* *} \quad .26^{* *} \quad--$

$\begin{array}{lllllll}\text { 6. Full-Time Farmers } & .10 & -.09 & .65 * * & .27 * * & .59 * * & --\end{array}$

7. Proportion Farmland $\quad .12 * \quad-.23 * * \quad .30^{* *} \quad .71 * * \quad .49 * * \quad .33^{* *} \quad \begin{array}{lllll}-- & \end{array}$ Note: $* * \mathrm{p}<.000 ; * \mathrm{p}<05$

Several of the independent measures feature strong correlations among one another, raising potential concerns regarding multicollinearity. This was assessed via an ordinary least squares (OLS) regression model containing the independent measures. Values for the multicollinearity diagnostics (tolerance and variance inflation factor) suggest that multicollineariy is not an issue in the current study. 


\section{Multivariate analysis}

The third stage utilizes a negative binomial regression model to determine the influence that each of the routine activity measures has upon farm equipment thefts. A full summary of the results is available in Table 3. They suggest a lack of support for two of the six hypotheses, as neither average farm size $(\beta=.00 ; p=.99)$ nor worker density $(\beta=-0.41 ; p=.49)$ emerge as statistically-significant predictors of theft incidence. However, the remaining measures are all revealed to be statistically-significant in the model.

Table 3: Negative-Binomial Model

\begin{tabular}{|c|c|c|c|}
\hline Measure & B & SE & $\mathbf{p}>|\mathbf{z}|$ \\
\hline Population Density & $0.00 * *$ & 0.00 & .00 \\
\hline Worker Density & -0.41 & 0.60 & .49 \\
\hline Equipment Value & $0.00 * *$ & 0.00 & .00 \\
\hline Average Farm Size & -0.00 & 0.00 & .99 \\
\hline Full-Time Farmers & $-1.85^{*}$ & 0.81 & .02 \\
\hline Proportion Farmland & $-0.98 *$ & 0.41 & .02 \\
\hline \multicolumn{4}{|l|}{ Note: $* * p<.000 ; * p<05$} \\
\hline \multicolumn{4}{|c|}{$\begin{array}{l}\text { Population density }(\beta=.00 ; \mathrm{p}=.00) \text { performs as hypothesized, with counties featuring } \\
\text { ner levels of density also experiencing higher incidence of theft. Equipment value }(\beta=.00 \text {; } \\
\text { 00), as anticipated, is also associated with increased theft prevalence. The remaining } \\
\text { sures (full-time farmers and proportion farmland) both feature negative relationships } \\
\text { farm equipment theft. Results are supportive of the hypothesis that a higher proportion } \\
\text { ull-time farmers }(\beta=-1.85 ; \mathrm{p}=.02) \text { will correspond with decreased theft incidence, but } \\
\text { trary to the prediction that counties featuring a higher proportion of farmland ( } \beta=-.98 \text {; } \\
02 \text { ) would feature increased counts of theft. }\end{array}$} \\
\hline
\end{tabular}

\section{Discussion}

The current study sought to identify measures that could be associated with routine activity theory at the macro level, and examine their impact upon incidence of farm equipment theft. Results of the analysis are on the whole supportive of the theory's application to the problem. In order to best understand the findings, it is useful to discuss them in relation to each of the research questions (and related hypotheses) explored. The initial hypothesis posited that counties featuring farms of higher average acreage would experience higher counts of farm equipment theft than those featuring farms of lower average acreage. This logic was based upon the findings of micro-level studies, as several have found that large farms are at greater risk of victimization (Dunkelberger et al., 1992; Farmer \& Voth, 1998; Mears et al., 2007). The current study, however, fails to provide support for the hypothesis, the measure was non-significant in the multivariate model. Though it is difficult to make inferences regarding the nature of this revelation, it is possible that other factors may better predict incidence of theft. For example, a higher proportion of full-time farmers within 
county (found to share a negative relationship with theft incidence) may make guardianship more effective, and counteract the increased victimization risk typically suggested (within the research literature) for larger farms.

The second hypothesis posited that counties featuring higher levels of population density would also experience higher incidence of farm equipment theft, and is supported by the results of the analysis. Understanding the impact of population density from a routine activity framework is somewhat complex due to the fact that it can theoretically be hypothesized to increase or decrease criminal offending. High-density areas feature more individuals interacting with the built environment on a regular basis, which may culminate in more criminal opportunities being within the awareness space of offenders (Wilcox et al., 2003). On the other hand, high levels of population density may present the potential for increased guardianship (Copes, 1999; Felson, 1994). Guardianship is dependent upon surveillance by both invested parties and others who may happen to be in the vicinity at the time. It would follow that surveillance - and as a result, guardianship - may be increased when more individuals are present.

In relation to the problem at hand, it appears as if population density serves to increase farm equipment theft prevalence - indicating that high density areas may present higher potential for motivated offenders to become aware of farm equipment that is left unguarded. This may be due to the geographical placement of farms, as they are typically located outside of populated business and housing districts. Even though a county may be densely-populated, the targets in which the offenders are acting upon are generally not within the surveillance area of a significant number of people. Nonetheless, they may still be located within the awareness space of offenders. Recent trends in housing have left many farms in proximity to housing developments located outside of population centers (Brown et al., 2005; Knight et al., 1995; Redman \& Foster, 2008). Consequently, they are located along roadways that experience a larger volume of daily traffic than was the case in the past (Barclay \& Donnermeyer, 2011). Most individuals traversing these roadways have no inclination to offend. However, some who are predisposed may become aware of an attractive target as a result of their daily commute, culminating in increased prevalence of theft.

Third, it was expected that counties featuring a higher on-average number of workers per farm would suffer from a higher incidence of farm equipment theft, in line with the findings of micro-level studies (Dunkelberger et al., 1992; McCall, 2003; Mears et al., 2007). This hypothesis was not supported, as the measure was non-significant in the multivariate model. It is possible that this finding is attributable to the nature of the Census of Agriculture. Farmers are asked to report the total number of workers who were employed by their operation during the prior year. They are not, however, asked whether the individuals worked full-time or part-time. It is plausible that this status (full-time or part-time) can have some impact upon theft incidence, as full-time workers may be more invested in the well-being of the farm and thus act as place managers (providing additional guardianship). Part-time workers, on the other hand, might be more likely to take advantage of theft opportunities or make others aware of them. In addition, it should be noted that some farmers may not 
accurately report the number of hired workers if they are "paid under the table". The popularity of migrant workers (Gonzales, 2015), some of whom are undocumented, may also make valid reporting less likely.

Fourth, it was hypothesized that counties featuring a higher aggregate value of equipment in use on farming operations would experience higher counts of theft. This hypothesis is supported by the results from the analysis, as total equipment value is positively associated with theft incidence. From a routine activity perspective, higher total values of equipment suggest the presence of more attractive targets. Past attempts to explore the applicability of routine activity theory at the macro level have found that areas featuring more attractive targets are at the greatest risk of experiencing crime (see Copes, 1999 for an example). This appears to be the case in relation to farm equipment theft as well. Even when controlling for other factors, it appears as if theft prevalence is influenced by the sheer number of opportunities present within a county.

The fifth hypothesis related to the expected increase in theft incidence for counties that feature a higher proportion of land dedicated to farming operations. Results suggest that the impact of land use works counter to this expectation, as a negative relationship emerged between the measure and incidence of theft. Past research (utilizing data for regions within Mexico) has suggested that the ready availability of farmland is correlated with reduced incidence of violent crime (Villarrael, 2004). It is possible that a similar effect could be seen with incidence of farm-related theft, and explained through elements of strain theory (the lack of economic strain presented by abundant farmland lessening the need and/or desire to turn to offending). Alternatively, counties comprised predominately of farmland may present the opportunity for close connections to be made between farm operators, and serve to increase shared guardianship of property through farm watch programs or other informal mechanisms.

The final hypothesis predicted that counties featuring a higher proportion of farmers claiming farming as a full-time occupation would suffer from fewer counts of theft, as fulltime status is likely to relate to the increased ability to effectively monitor property (and thus guard against theft). As detailed in the findings, results are supportive of this logic. Recent years have witnessed an increase in the number of part-time farm operators, as many have turned to other occupations out of economic necessity. For example, results from the 2012 Census of Agriculture suggest that over $50 \%$ of all farming operations are owned by individuals who hold at least one other form of employment (U.S. Department of Agriculture, 2012). It is plausible that the incidence of theft nationwide may increase as this number continues to grow. Further, the increasing popularity of leasing farmland (see Nickerson et al., 2012) may also impact theft incidence, as this property is typically not adjacent to the lease holder's residence. Though not investigated in the current work, the finding that fulltime status is related to county-level counts of equipment theft promotes the need for further inquiry into the impact of such macro-level trends on the problem. 


\section{Limitations}

Though it offers a unique perspective on the applicability of routine activity theory to farm equipment theft, the study is not without limitations. First, NIBRS has in the past been found to feature problems with missing and/or miscoded data (Liao et al., 2015; Thompson et al., 1999). Participating agencies are provided with a user manual and various training programs to ensure that all crime incidents are coded properly (Barnett-Ryan \& Swanson, 2008). However, the lack of audits (by federal and state agencies) prevents a thorough understanding of the effectiveness of this training. In light of this, it is possible that reported theft counts (by county) may not be fully reflective of theft incidence.

Second, not all measures employed in micro-level studies are able to be tested at the macro level due to a lack of available data. For example, target-hardening measures have been found to be influential in structuring victimization risk due to increased guardianship of property (as previously discussed). However, aggregating measures related to guardianship (e.g., use of locks, gates, surveillance cameras) would require surveying farmers within each county.

Third, and finally, it is important to note that the Census of Agriculture (2007) was conducted four years prior to the years for which counts of the dependent measure are taken (2011 and 2012). As such, the use of the 2007 version of the Census may not accurately represent the characteristics of farming operations in the years 2011-2012. With that said, the Food and Agriculture Organization of the United Nations promotes a time period of every ten years as being suitable for the collection of agricultural census data, as structural characteristics of farming tend to change somewhat slowly over time (FAO, 2010). Thus, the fact that the gap in question is only four years in duration provides some confidence in the use of the 2007 version.

\section{Conclusion}

In spite of the discussed limitations, the current study offers much to our understanding of farm equipment theft. This constitutes the first attempt to determine the relationship between macro-level characteristics and incidence of theft from farming operations. Its findings suggest that these broad societal forces may in fact structure the aggregate incidence of equipment theft, and calls for further exploration of this and other possible factors that may similarly impact the problem. In addition, it offers continued support for the notion that routine activity theory may assist in explaining farm equipment theft and that the theory has applicability to macro-level problems in rural communities. 


\section{References}

Barclay, E., \& Donnermeyer, J. F. (2011). Crime and security on agricultural operations. Security Journal, 24, 1-18. https://doi.org/10.1057/sj.2008.23

Barnett-Ryan, C., \& Swanson, G. (2008). The role of state programs in NIBRS data quality: A case study of two states. Journal of Contemporary Criminal Justice, 24, 18-31. https://doi.org/10.1177/1043986207312590

Brown, D. G., Johnson, K. M., Loveland, T. R., \& Theobald, D. M. (2005). Rural land-use trends in the conterminous United States, 1950-2000. Ecological Applications, 15, 1851-1863. https://doi.org/10.1890/03-5220

Bunei, E. K., \& Barasa, F. O. (2017). Farm crime victimisation in Kenya: A Routine activity approach. International Journal of Rural Criminology, 3, 224-249. https://doi.org/10.18061/1811/81046

Chen, P.Y., \& Popovich, P.M. (2002). Correlation: Parametric and nonparametric measures. Thousand Oaks, CA: Sage. https://doi.org/10.4135/9781412983808

Cleland, C. L. (1990). Crime and vandalism on farms in Tennessee: Farmer opinions about and experience with. Knoxville, TN: University of Tennessee.

Cohen, L. E., \& Felson, M. (1979). Social change and crime rate trends: A routine activity approach. American Sociological Review, 44, 588-608. https://doi.org/10.2307/2094589

Copes, H. (1999). Routine activities and motor vehicle theft: A crime specific approach. Journal of Crime and Justice, 22, 125-146. https://doi.org/10.1080/0735648X.1999.9721097

Dunkelberger, J. E., Clayton, J. M., Myrick, R. S., \& Lyles, G. J. (1992). Crime and Alabama farms: Victimization, subjective assessment, and protective action. Alabama Agricultural Experiment Station.

Food and Agriculture Organization of the United Nations (2010). A system of integrated agricultural censuses and surveys. Rome: FAO Statistical Development Series, Volume 1.

Farmer, F. L., \& Voth, D. E. (1989). Ecological characteristics of farm victimization in Arkansas. Fayetteville, AR: Arkansas Agricultural Experiment Station. 
Felson, M. (1994). Crime and everyday life: Insights and implications for society. Thousand Oaks, CA: Pine Forge Press.

Felson, M., \& Clarke, R. V. (1998). Opportunity makes the thief (Police Research Series, No. 98). London, England: Home Office.

George Street Research. (1999). Crime and the farming community: The Scottish Farm Crime Survey. Edinburgh: The Scottish Office Central Research Unit.

Gonzales, E. (2015). Migrant farm workers: Our nation's invisible population. Ithica, NY: Cornell University Cooperate Extension.

Green, E. K. (2016). Culture conflict between moonshiners and the government: An explanation of jury nullification and Nolle Prosequi in illicit alcohol offenses in rural communities. International Journal of Rural Criminology, 3, 50-67. https://doi.org/10.18061/1811/78045

Green, E.K. (2011). Telephoning fish: An examination of the creative deviance used by wildlife violators in the United States. International Journal of Rural Criminology, 1, 23-39. https://doi.org/10.18061/1811/51128

Hardin, J. W., \& Hilbe, J. W. (2012). Generalized linear models and extensions. College Station, TX: Stata Press.

Hilbe, J. (2011). Negative binomial regression. Cambridge, UK: Cambridge University Press. https://doi.org/10.1017/CBO9780511973420

Knight, R. L., Wallace, G. N., \& Riebsame, W. E. (1995). Ranching the view: Subdivisions versus agriculture. Conservation Biology, 9, 459-461. https://doi.org/10.1046/j.15231739.1995.9020459.x

Liao, D., Berzofsky, M., Heller, D., Barrick, K., \& DeMichele, M. (2015). Treatment of missing data in the FBI's national incident based reporting system: A case study in the Bakken region. In Joint Statistical Meetings, August 2015 (pp. 1970-1981).

McCormack, P. D., Pattavina, A., \& Tracy, P. E. (2017). Assessing the coverage and representativeness of the National Incident-Based Reporting System. Crime \& Delinquency, 63, 493-516. https://doi.org/10.1177/0011128717694595

McCall, M. (2003). Results from the 2001-2002 national farm crime survey. Trends \& Issues in Crime and Criminal Justice, No. 266. Canberra: Australian Institute of Criminology. https://aic.gov.au/publications/tandi/tandi266 
McIntyre Jr, R. N., Prine, R. K., \& Knowles, F. (2017). An exploratory assessment of agricultural crimes in Georgia. International Journal of Rural Criminology, 3, 157175. https://doi.org/10.18061/1811/81049

Mears, D. P., Scott, M. L., \& Bhati, A. S. (2007). Opportunity theory and agricultural crime victimization. Rural Sociology, 72, 151-184. https://doi.org/10.1526/003601107781170044

Messner, S. F., \& Blau, J. R. (1987). Routine leisure activities and rates of crime: A macrolevel analysis. Social Forces, 65, 1035-1052. https://doi.org/10.2307/2579022

Mortimer, M. J., Baker, S., \& Shaffer, R. M. (2005). Assessing and understanding timber trespass and theft laws in the Appalachian Region. Northern Journal of Applied Forestry, 22, 94-101. https://doi.org/10.1093/njaf/22.2.94

National Agriculture Statistics Service. (2014). Census of Agriculture (2012). Washington, D.C.: United State Department of Agriculture.

Nickerson, C., Morehart, M., Kuethe, T., Beckman, J., Ifft, J., \& Williams, R. (2012). Trends in US farmland values and ownership. Publications from USDA-ARS. Lincoln, NE: Agricultural Research Service. http://digitalcommons.unl.edu/usdaarsfacpub/1598

Redman, C., \& Foster, D. (2008). Agrarian landscapes in transition: Comparisons of longterm ecological and cultural change (Long-Term Ecological Research Network Series). New York, NY: Oxford University Press.

Roman, C. G., Reid, S.E., Bhati, A.S., \& Tereshchenko, B. (2008). Alcohol outlets as attractors of violence and disorder: A closer look at the neighborhood environment. Washington, D.C.: Urban Institute. https://doi.org/10.1037/e513432010-001

Serenari, C., \& Peterson, M. N. (2016). A sociopolitical perspective on the illegal take of wildlife in the Southeastern, USA. International Journal of Rural Criminology, 3, 29 49. https://doi.org/10.18061/1811/78046

Smith, W. R., Frazee, S. G., \& Davison, E. L. (2000). Furthering the integration of routine activity and social disorganization theories: Small units of analysis and the study of street robbery as a diffusion process. Criminology, 38, 489-524. https://doi.org/10.1111/j.1745-9125.2000.tb00897.x

Swanson, C.R., Chamelin, N.C., \& Territo, T. (2002). Criminal investigation. Boston, MA: McGraw Publishing. 
Thompson, M. P., Saltzman, L. E., \& Bibel, D. (1999). Applying NIBRS data to the study of intimate partner violence: Massachusetts as a case study. Journal of Quantitative Criminology, 15, 163-180. https://doi.org/10.1023/A:1007522721430

U.S. Department of Justice, (2017). National Incident-Based Reporting System User Manual. Washington, D.C.: Criminal Justice Information Services Division, U.S. Department of Justice.

Villarreal, A. (2004). The social ecology of rural violence: Land scarcity, the organization of agricultural production, and the presence of the state. American Journal of Sociology, 110, 313-348. https://doi.org/10.1086/421724

Wilcox, P., Quisenberry, N., Cabrera, D. T., \& Jones, S. (2004). Busy places and broken windows? Towards defining the role of physical structure and process in community crime models. The Sociological Quarterly, 45, 185-207. https://doi.org/10.1111/j.1533-8525.2004.tb00009.x

Wilcox, P., Land, K. C., \& Hunt, S. A. (2003). Criminal circumstance: A dynamic multicontextual criminal opportunity theory. New Jersey: Transaction Publishers 